\title{
Em busca do tempo vivido
}

$O$ discurso psicológico na SBPC, de Paulo Rosas ${ }^{1}$

Denis Barros de Carvalho

Universidade Federal do Rio Grande do Norte

(...) a ciência se mostra constantemente determinada pelo seu desenvolvimento histórico. Sua historicidade exprime um traço intrínseco definidor de sua realidade, e não deve ser confundida com a simples cronologia dos momentos culminantes do seu progresso.

Álvaro Vieira Pinto

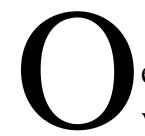
eminente filósofo brasileiro Raimundo Farias Brito (1912), em um texto escrito na primeira década deste século, descre ve o desenvolvimento histórico da Psicologia no mundo e no Brasil, apontando o rápido crescimento dessa área de estudo no mundo, afirmando - contudo - que em nosso meio nada havia digno de menção e que "o solo da intelectualidade nacional não parece ser terreno propício para a semente da nova ciência” (p. 277). A história, porém, mostrou que a Psicologia se desenvolveu bem no Brasil e veio a se tornar uma das áreas do conhecimento que mais se expandiu em nosso contexto. Por que ocorreu esse interesse? O que possibilitou a transformação do aparente árido solo da intelectualidade brasileira em um terreno propício para o florescimento da Psicologia? Atualmente, 
os historiadores ${ }^{1}$ têm um renovado interesse pelas fontes primárias e secundárias que podem ser utilizadas para o desvelamento dos fatos que determinaram a atual configuração da Psicologia nacional. Uma das principais fontes para a historiografia das ciências são, com certeza, os trabalhos publicados pelos pesquisadores. Artigos publicados em periódicos, anais de encontros e livros - para citar apenas os mais evidentes - são elementos indispensáveis para a pesquisa historiográfica. Por isso, considero muito oportuna a publicação do livro $O$ discurso psicológico na $S B P C$, do professor Paulo Rosas.

A Sociedade Brasileira para o Progresso da Ciência (SBPC) foi fundada em 1948, com o propósito de promover o intercâmbio e o debate entre cientistas e pesquisadores dos vários campos da tecnologia e da ciência. Além disso, a principal característica da SBPC é a sua abertura para todas as ciências. O próprio conceito de ciência, implicitamente norteador dessa instituição - pelo menos a partir da década de setenta - é amplo o suficiente para acolher pesquisadores de áreas como a Filosofia, a Educação e as Ciências Humanas (Fernandes, 1990).

Paulo Rosas descreve os trabalhos de Psicologia apresentados nas reuniões anuais da SBPC e dos textos publicados na revista Ciência e Cultura (editada por aquela entidade), de 1949 a 1988. Como elemento de comparação, Rosas apresenta os textos psicológicos publicados no mesmo período nos Arquivos Brasileiros de Psicotécnica e na Revista Brasileira de Estudos Pedagógicos. A apresentação dos resultados obedece a uma seqüência temporal, sendo os trabalhos classificados em dez categorias: Formação e treinamento de psicólogos, Psicologia Geral/História da Psicologia, Psicologia Experimental/Psicobiologia, Psicologia Social/Personalidade, Psicologia Cognitiva, Psicologia Educacional/Psicologia Escolar, Psicologia do Desenvolvimento, Psicologia Clínica/Psicanálise, Psicometria/Testes psicológicos, Psicologia do Trabalho, Orientação Profissional e outros temas. Infelizmente, a junção dos trabalhos de Psicologia Geral e de História da Psicologia não nos permite analisar o desenvolvimento do interesse pela história da Psicologia em nosso país.

Rosas partiu do pressuposto de que o discurso psicológico exposto nas Reuniões Anuais da SBPC foi um importante indicador do 
desenvolvimento da pesquisa psicológica no Brasil. O termo discurso foi utilizado no sentido de exposição metódica, fundada ou não em pesquisa. Essa opção, talvez motivada pelo desejo de maior praticidade na catalogação dos dados, falha por não permitir avaliar com precisão o que foi produzido em pesquisas e o que é apenas reflexão teórica ou até mesmo opinião pessoal.

As principais conclusões desse livro podem ser resumidas assim:

1) A SBPC exerceu um papel estimulador no que diz respeito à realização de pesquisas e estudos psicológicos.

2) A SBPC desempenhou um importante papel estimulador na formação de uma atitude de pesquisa, principalmente por ceder espaço para apresentação de trabalhos de estudantes e jovens cientistas.

3) As reuniões da SBPC expressaram as tendências predominantes na Psicologia brasileira. O maior número de trabalhos acerca da psicometria e dos testes psicológicos no período de 1949 a 1968, por exemplo, corresponde à hegemonia dos testes psicológicos nas práticas psicológicas de então.

4) A Psicologia Clínica foi um tema pouco trabalhado na SPBC nos dois primeiros decênios das suas reuniões. É possível que um certo preconceito então vigente no que diz respeito à suposta obrigatoriedade de quantificação e objetividade em Psicologia tenha afastado os psicólogos clínicos e os psicanalistas, que preferiram comunicar seus achados e idéias em publicações e reuniões específicas. Isso pode explicar a pouca participação de trabalhos clínicos e psicanalíticos nas duas primeiras décadas de reuniões da SBPC, mas não explica o seu crescimento posterior, questão que eu acho mais importante e a que Rosas não deu a devida atenção.

Gostaria de tecer alguns comentários acerca dessa última afirmação: como mostram os dados da Tabela 13 (p.100), a apresentação de trabalhos classificados na categoria Psicologia Clínica/Psicanálise sempre esteve em um crescendo, apresentando um total de 200 trabalhos (para efeito de comparação: a categoria psicometria/testes psicológicos teve um total de 181 trabalhos), sendo que no período de 1979 a 1988 foram apresentados 154 comunicações.

O que possibilitou tal crescimento impressionante nesse último período? Imre Lakatos (1989), importante filósofo contemporâneo, 
chama atenção para a importante diferença entre historiografia internalista e externalista nos estudos da história da ciência. A abordagem internalista procura reconstruir a lógica da descoberta científica e da elaboração dos modelos de análise da realidade a partir da evolução do conhecimento expresso nas publicações científicas. A abordagem externalista, por sua vez, analisa o impacto do contexto sociocultural e do desenvolvimento histórico da sociedade sobre as idéia científicas.

A abordagem externalista pode nos ajudar a entender o crescimento de comunicações de trabalhos classificados como Psicologia Clínica/Psicanálise no período de 1979 a 1988. De acordo com o psicanalista Sérvulo Figueira (1981, 1985), a Psicanálise teve uma maciça divulgação na sociedade brasileira a partir da década de setenta, vindo a responder a uma necessidade social de orientação por parte das pessoas afetadas pela modernização intensificada a partir da década de 50, expressa por mudança econômicas, políticas e, principalmente, pela célere urbanização pela qual passou o nosso país. As classes médias e altas urbanas passaram a cultivar um ethos individualista caracterizado pela centralidade do "valor" indivíduo ${ }^{3}$ e pela nuclearização da família. Cecília Coimbra (1993, 1995) aponta como nos anos setenta e oitenta houve uma ênfase na privatização e nuclearização da família, gerando um culto da intimidade e do individualismo ${ }^{4}$, em contraste com os valores patriarcais da antiga família hierárquica. Como conseqüência, surge uma maior responsabilidade individual de cada um dos membros da família, principalmente na escolha de companheiros e na atividade profissional, na descoberta de sua "autenticidade" e na "libertação" das repressões promovidas pelos valores antigos. Além disso, a profunda crise da sociedade brasileira impôs a busca de um refúgio no próprio sujeito para a produção de valores norteadores do comportamento individual ${ }^{5}$. A busca por um sucedâneo da tradição e da religiosidade fez com que a Psicanálise e a Psicologia Clínica (caracterizada por e quase confundida com psicoterapia) passassem a ter uma grande importância nas determinações dos saberes competentes acerca das práticas cotidianas que expressam, para usar uma expressão de Giddens (1996), uma política da vida ${ }^{6}$. 
5) Os estudos de Psicologia Experimental e de Psicobiologia tiveram um significativo crescimento nas reuniões anuais da SBPC, chegando a constituir 55\% de todos os trabalhos apresentados em Psicologia no período de 1979 a 1988. Conforme Rosas, contudo,

apesar da grande produção de pesquisas no domínio da psicobiologia e da psicologia experimental, trata-se de uma produção gerada em alguns centros acadêmicos, de modo algum cabendo considerá-la como tendência predominante entre os psicólogos no Brasil (p. 97).

Concordamos com essa afirmação, mas creio que teria sido interessante que Rosas apresentasse uma tabela indicando a distribuição de trabalhos por instituições, tanto da produção geral, quanto por áreas temáticas. Concomitantemente, para efeito de comparação, seria interessante verificar como se distribuíram por temas os trabalhos apresentados nas reuniões anuais da Sociedade Brasileira de Psicologia em Ribeirão Preto (SP), em que a Psicologia era a única área de conhecimento em pauta em um evento promovido por e para psicólogos.

6) As reuniões anuais da SBPC são encaradas hoje como encontros importantes para estudantes e pesquisadores iniciantes, mas pouco válidas como oportunidade de intercâmbio científico para especialistas mais avançados. Não seria interessante pesquisar a participação dos "especialistas mais avançados" ao longo dos anos para verificar essa afirmação? Na verdade, ela expressa apenas uma impressão pessoal (claro que não infundada). Não poderia ser tema de uma investigação mais acurada? Além disso, seria necessário avaliar se os participantes mais experientes não estariam procurando fóruns mais específicos como as reuniões de Ribeirão Preto, os encontros de Etologia, Psicologia Hospitalar, Escolar, Organizacional etc. Os encontros anuais da SBPC não seriam mais procurados pelos psicólogos mais experientes por estes procurarem espaços mais especializados. Eu creio que seria interessante produzir mais pesquisas acerca dessas questões.

Como afirmamos no início desta resenha, reputamos como muito oportuna a publicação de mais um trabalho do professor Paulo Rosas, que vem se somar aos trabalhos de orientação internalista da historio- 
grafia da Psicologia no Brasil, como os de Antônio Gomes Pena (1978, 1980, 1992) e Isaias Pessotti (1988), além de trabalhos anteriores do próprio Rosas $(1995,1997)$, dentre outros.

\section{Agradecimento}

Agradeço ao professor Herculano Campos pela leitura e sugestões referentes a esta resenha. Agradecimentos ao CNPq pelo apoio (Processo n $\left.{ }^{\circ} .520218 / 96-5\right)$.

\section{Referências}

Brito, R. F. (1912). A base fisica do espirito: história sumária do problema da mentalidade como preparação para o estudo da filosofia do espírito. Rio de Janeiro: Livraria Alves.

Coimbra, C. M. B. (1993). A produção de subjetividade nos anos 70 e as Práticas "Psi". In J. F. Silva \& J. A. Russo. (Orgs.), Duzentos anos de psiquiatria (pp. 59-70). Rio de Janeiro: Relume Dumará/ Editora da UFRJ.

Coimbra, C. M. B. (1995). Guardiões da ordem: uma viagem pelas práticas psi no país do "Milagre”. Rio de Janeiro : Oficina do autor.

Fernandes, A. M. (1990). A construção da ciência no Brasil e a SBPC. Brasília: Editora da UnB.

Figueira, S. (1981). O contexto social da psicanálise. Rio de Janeiro: Francisco Alves.

Figueira, S. (Org.). (1985). Cultura da psicanálise. São Paulo: Brasiliense.

Figueiredo, L. C. (1991). Psicologia.: uma introdução. Uma visão histórica da psicologia como ciência. São Paulo: Editora Universidade Católica.

Giddens, A. (1993). A transformação da intimidade: sexualidade, amor \& erotismo nas sociedades modernas. São Paulo: Editora Unesp.

Giddens, A. (1996). Para além da Esquerda e da Direita. São Paulo: Editora Unesp.

Lakatos, I. (1989). La metodologia de los programas de investigación cientifica. Madri: Alianza Editora.

Lasch, C. A. (1983). Cultura do narcisismo: a vida americana numa era de esperanças em declínio. Rio de Janeiro: Imago. 
Lasch, C. A. (1990). O mínimo eu: Sobrevivência psíquica em tempos dificeis. São Paulo: Brasiliense.

Pena, A. G. (1978). Introdução à história da psicologia contemporânea. Rio de Janeiro: Zahar.

Pena, A. G. (1980). História das idéias psicológicas. Rio de Janeiro: Zahar Editores.

Pena, A. G. (1992). História da psicologia no Rio de Janeiro. Rio de Janeiro: Imago.

Pessotti, I. (1988). "Notas para uma história da psicologia brasileira, In Conselho Federal de Psicologia (Org.), Quem é o psicólogo brasileiro? (pp.17-31). São Paulo: Edicon.

Pinto, A. V. (1979). Ciência e existência. Rio de Janeiro: Paz e Terra.

Rosas, P. (1995). Mira y López, 30 anos depois. São Paulo: Vetor.

Rosas, P. (1997). O ISOP no tempo de Mira. In S. B. Silva \& P. Rosas (Orgs.), Mira López e a psicologia aplicada no Brasil. Rio de Janeiro: Fundação Getúlio Vargas.

Rosas, P. (1998). O discurso psicológico na SBPC. Recife: Editora da Universidade Federal de Pernambuco.

\footnotetext{
Nota ${ }^{1}$ O discurso psicológico na SBPC, de Paulo Rosas (Recife: Editora da Universidade Federal de Pernambuco, 1998).

2 Na verdade, a história da Psicologia brasileira tem sido escrita por psicólogos que desejavam descrever o processo de formação histórica de sua ciência.

3 Bem expresso pela afirmação crítica de Figueira (1981, p. 9): “o sujeito psicológico passa, de fato, a ser a medida de todas as coisas..."

4 É bom lembrar que esta mudança caracteriza o surgimento das sociedades modernas. Para um estudo acerca dessa transformação em outras sociedades (principalmente na estadunidense), ver Lasch (1983, 1990) e Giddens (1993, 1996).
} 
334 Resenha

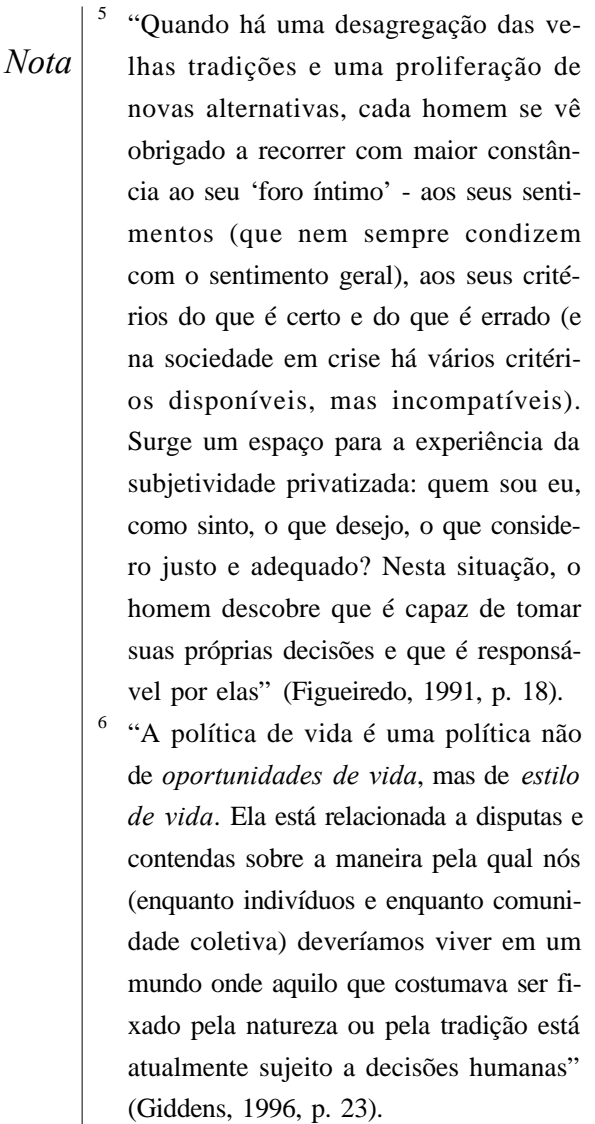

Denis Barros de Carvalho é psicólogo, formado pela UFRN, membro do Grupo de Pesquisas Marxismo \& Educação (GPME). Bolsista de Aperfeiçoamento do Conselho Nacional de Desenvolvimento Científico e Tecnológico (CNPq), autor de vários trabalhos publicados em revistas especializadas. Endereço para correspondência: Alameda das Cerejeiras, $n^{\circ} 175$, Neópolis, Natal -RN, 59080-360. Email: denis@eol.com.br.

\section{Sobre o autor}

